\title{
TWO CASES OF \\ BASILAR ARTERY OCCLUSION IN CHILDHOOD
}

BY

\author{
MALCOLM FOWLER \\ From Adelaide Children's Hospital, Adelaide, South Australia
}

(RECEIVED FOR PUBLICATION JULY 11, 1961)

Basilar artery occlusion is not a diagnosis which is frequently made, although, since the clarification of the clinical manifestations by Kubik and Adams (1946), more cases are being recognized. The following two cases are reported because no instances of basilar artery occlusion in childhood have been found in the literature, and because in one of the patients the occlusion was a completely isolated event in an otherwise normal child.

\section{Case Reports}

Case 1. The patient, a female aged 18 months, was admitted to the Adelaide Children's Hospital on December 6, 1959, after having fallen on to burning grass. She had suffered deep burns to the heels and feet, and more superficial burns to the buttocks and perineum. The toes of both feet and the tips of some of the fingers eventually became completely necrotic and were sloughed.

Skin grafting was attempted on December 23, but this was unsuccessful because of heavy infection on the burned surfaces. Despite a raised temperature (up to $103^{\circ} \mathrm{F}$.) her clinical state from December 15 was satisfactory until December 31 when she passed through a short period of shock with a temperature of $105^{\circ} \mathrm{F}$. On December 30, the gum over the central part of the lower jaw was noticed to be receding from her teeth, and this process extended until the bone was exposed and all the lower incisors were shed. A further skin graft to the hands and feet on January 8, 1960 was successful. Sudden unconsciousness occurred on January 14 , the patient responding vaguely to painful stimuli. Neurological examination showed fixed, moderately dilated pupils, the left being larger than the right. The limbs were flaccid, all being moved on stimulation, the left side perhaps more actively than the right. There was no other evidence of impairment of motor cranial nerves.

Bifrontal burr-holes were made and a ventriculogram showed no abnormality. Her condition, including the pyrexia, remained unchanged until her death on January 19.

Post-mortem Examination. The autopsy (A.C.H. No. $=2 / 60$ ) was performed 28 hours after death. The skin lesions were recorded, and it was noted that several teeth were missing from the lower jaw. Examination of the brain showed intense congestion of the arachnoid and purulent subarachnoid exudate which was most marked around the inferior surfaces of the temporal and right frontal lobes. In the cranial end of the basilar artery, occluding both superior cerebellar arteries and extending into both posterior cerebral arteries, was a pale firm thrombus (Fig. 1). The posterior communicating arteries were very slender. After fixation, pale brown areas of softening were found in the midbrain involving the cerebral peduncles and the tegmentum, much more severe on the right side. In the ventrolateral nucleus of both thalami was an area of softening, each about $1 \mathrm{~cm}$. $\times 0.5 \mathrm{~cm}$. wide in cross-sectional area, the length not being recorded. A small abscess, approximately $0.5 \mathrm{~cm}$. in diameter was present in the central white matter of the right frontal lobe and another smaller similar area in the corpus callosum. There were no relevant macroscopic findings in the other organs. Culture of post-mortem blood yielded a mixed growth of coagulase-positive Staph. aureus and Group A haemolytic streptococci, and from the meninges haemolytic streptococci (Group A) and a few Staph. aureus were isolated.

Microscopic examination showed tiny infective foci

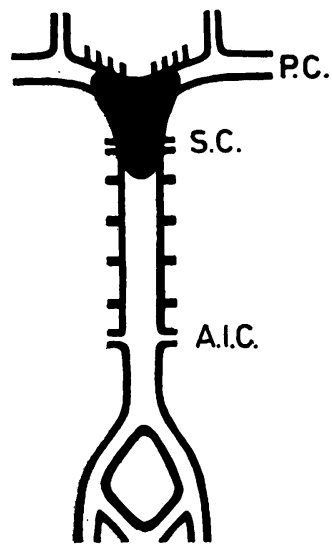

FIG. 1.-Case 1: diagram of thrombus in basilar artery. P.C. = post communicating; S.C. = superior cerebellar: A I.C. = anterior inferior cerebellar 


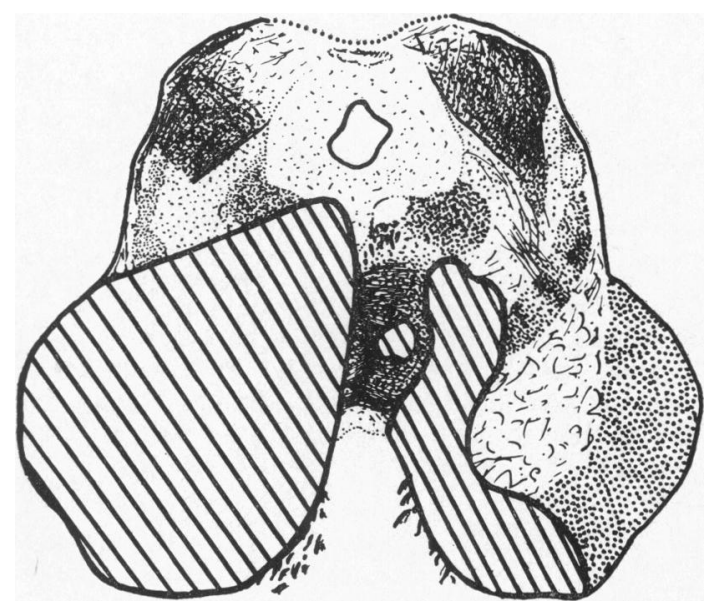

FIG 2-Case 1: diagram of midbrain; the softening is indicated by stripes

of neutrophils in the liver, spleen, kidney and myocardium, often associated with intravascular colonies of bacteria, and confirmed the presence of a purulent meningitis and small intracerebral abscesses. In the lower jaw there was strikingly little evidence of infection, the alveolar margins being necrotic and in the process of sequestration through a moderately inflamed surface granulation tissue. The mandible showed subperiosteal new bone formation particularly on its inferior surface, but its medulla and cortex were free from inflammation, and there were no thrombi in its vessels. The lesion in the right side of the midbrain involved nearly the whole cerebral peduncle, the substantia nigra, the brachium conjunctivum, most of the medial lemniscus and the central tegmental tract, the medial longitudinal bundle and the emerging fibres of the oculomotor nerve (Fig. 2). The nucleus of the trochlear nerve was spared at this level. On the left side much of the cerebral peduncle and the medial part of the substantia nigra had been destroyed with a narrow extension into the tegmentum to involve about half of the lateral part of the brachium conjunctivum, the medial half of the medial lemniscus, and the oculomotor fibres. The necrosis on both sides extended cranially to involve the red nuclei. As only one level of the thalamus on each side was sectioned the extent of the damage here was not certain. The cerebellum and occipital lobes showed no evidence of infarction. The thrombus in the basilar artery consisted of fused platelets and fibrin with the scattered nuclear debris of neutrophil leucocytes and a few lysed red blood cells. No organization had occurred, and the slight lamination of the elements of the thrombus that had taken place was confused and ill defined. Numerous bacterial colonies were present in the central parts of the thrombus but not on the periphery. The wall of the artery (not serially sectioned) contained a few tiny foci of neutrophil leucocytes under its intima, and there was one area of early superficial necrosis of the muscular wall without any inflammatory reaction. The muscle coat was thinner than normal as a result of distension by the thrombus.

Case 2. The patient, a boy aged 7 years and 4 months, with no previous history of any serious illness and apparently in the best of health, was found in a comatose state in his bed one morning. Urine and faeces had been passed into the bed. Two other children in the same room had not been disturbed during the night. His aunt, with whom he was staying, said that he had seemed very thirsty during the previous few days. The family history contained no immediately relevant features; an aunt was a diabetic.

On admission, three hours after being found in this state, he was still in coma, responding briefly but purposelessly under painful stimulation. His general condition was good, with a warm skin, good colour, normal pulse, and no fever. There was a small healing abrasion on his back, but apart from this no abnormalities were found except in the nervous system. The pupils were small, but varied slightly in size from time to time, and sometimes reacted sluggishly to light, although mostly they were unresponsive. The fundi oculorum were normal. There was a mild left facial nerve palsy. The tendon reflexes on both sides of the body were hyperactive and the plantar responses were extensor. No neck stiffness was detected but Kernig's sign was positive. The cerebrospinal fluid was under normal pressure, contained $20 \mathrm{mg}$. protein per $100 \mathrm{ml}$. and no cells. The blood urea nitrogen measured $18 \mathrm{mg}$. and the blood sugar $100 \mathrm{mg}$. per $100 \mathrm{ml}$. The white blood cells numbered 14,000 per c.mm. The blood pressure was $120 \mathrm{~mm}$. $\mathrm{Hg}$ systolic and $80 \mathrm{~mm} . \mathrm{Hg}$ diastolic. Ward tests revealed some acetone in the urine but no reducing sugar. Radiographs of the skull showed no abnormality.

Over the first three days after admission his level of consciousness was thought to have improved slightly, the left facial paresis became more definite, and the pupils began to react sluggishly to light. Four days after admission he began to have attacks of generalized extensor spasm, lasting for a minute. After some weeks of these attacks, the rigidity of the extensor muscles became permanent, with persistent head retraction. A right carotid arteriogram was performed without showing any abnormality. Further lumbar punctures at various times throughout the illness revealed normal cerebrospinal fluid. He died 10 weeks after admission with signs of pneumonia.

Post-mortem Examination. The autopsy (A.C.H. No. 21/60) was performed seven hours after death. Apart from general emaciation and bronchopneumonia the significant findings were confined to the nervous system. In the left posterior cerebral artery, immediately distal to the basilar artery, was a small semi-translucent swelling in the lumen, about $3 \mathrm{~mm}$. long (Fig. 3). Slicing of the brain after fixation showed spongy yellowish areas of softening in the ventrolateral nucleus of both thalami (Fig. 4), that on the left being slightly larger than that on the right which measured approximately $1.0 \times 0.5 \times 0.5 \mathrm{~cm}$. In the midbrain tegmentum on 


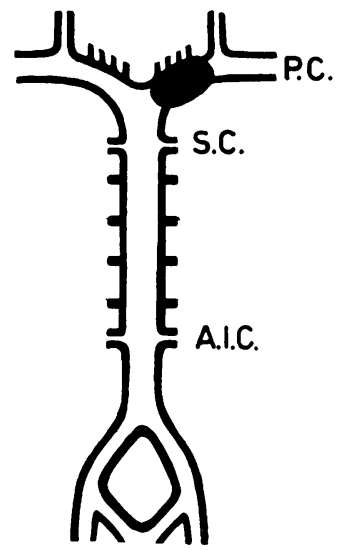

FIG 3.-Case 2: diagram of thrombus in left posterior communicating artery.

the right side was a faint yellowish hairlike serpiginous area. The cerebral arteries were otherwise normal. The cervical portions of the vertebral arteries were shown to te patent and the cervical vertebrae were normal radiologically.

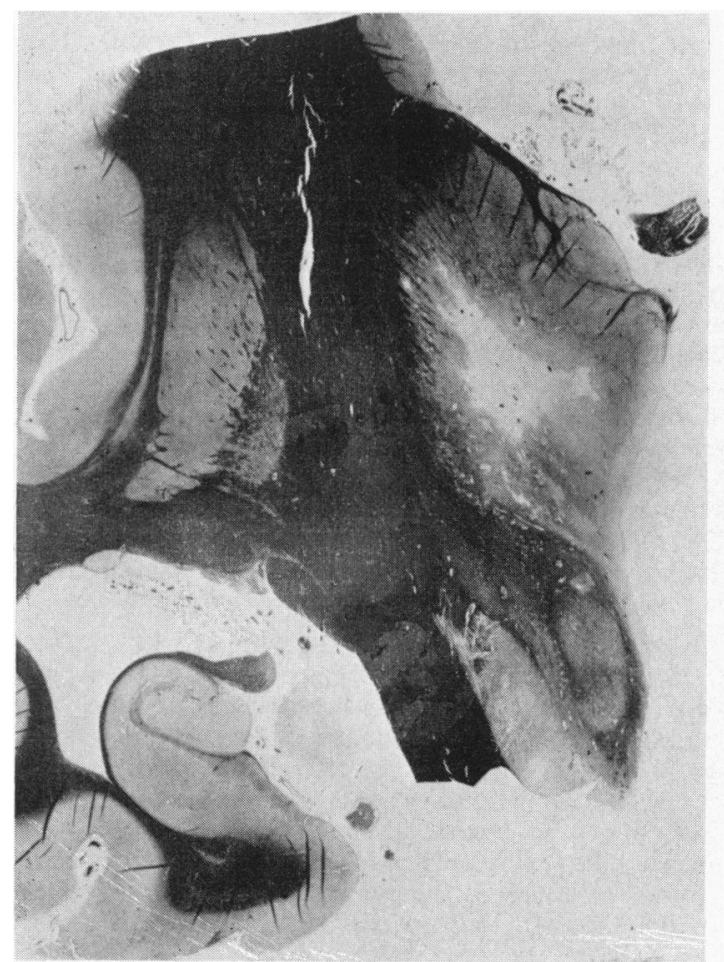

Microscopic examination confirmed the presence of bronchopneumonia and showed normal kidney, myocardium, spleen, pancreas and suprarenal. The obstruction in the left posterior cerebral artery was a partially organized thrombus occupying the whole lumen, but a small recanalizing sinusoid was present towards one edge. The softened areas in the ventrolateral nuclei of the thalami were well organized consisting of a network of capillaries and foamy macrophages, while around them for a considerable distance there was loss of neurones accompanied by proliferation of astrocytes and microglial nuclei. On examination of serial sections of the midbrain very small single foci of softening just visible to the naked eye were found in the left substantia nigra, in the left brachium conjunctivum and in the left cerebral peduncle. In the superior part of the left red nucleus there was an increase in microglial nuclei.

\section{Discussion}

Although several authors had previously dealt with obstruction of the basilar artery, the most comprehensive account, based on 18 cases brought to autopsy, is that of Kubik and Adams in 1946. Their youngest patient was a female aged 32 who suddenly developed occipital headache, nausea and vomiting, shortly after being delivered of her third

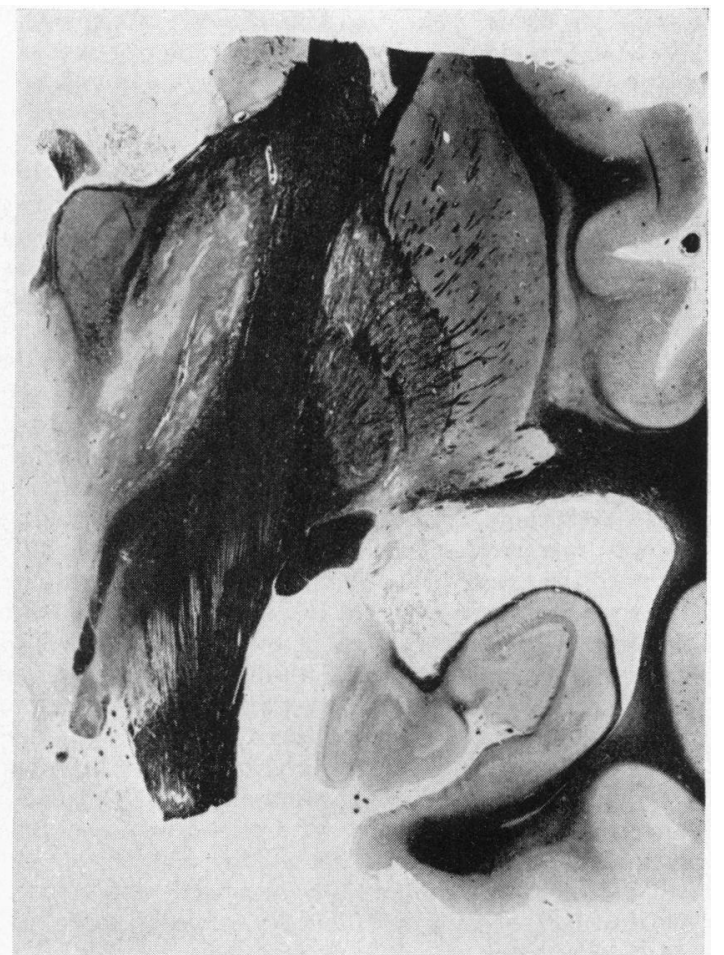

Fig. 4.-Case 2: sections to show areas of softening in the ventrolateral nuclei of both thalami (Weil stain). 
child, and went into coma with hemiplegia and fixed dilated pupils. Death ensued on the seventh day and at autopsy an embolus was found occluding the anterior end and bifurcation of the basilar artery. The embolus was thought to have been associated with bacterial endocarditis, but as autopsy was limited to the head the final proof of this is lacking. Eleven of their 18 cases were due to thrombosis and as might be expected the basilar artery in these cases was atheromatous. Biemond (1951) reported four cases, the youngest a woman of 39 whose basilar artery at its anterior end had been occluded by silver clips during removal of a tumour from the cerebello-pontine angle. Cravioto, Rey-Bellet, Prose and Feigin (1958) described 14 autopsied cases, the youngest aged 46 . The pathogenesis of the obstruction in several of their cases, both embolic and thrombotic, could not be explained. The youngest patient previously reported is that of Hansen (1958) who in a series of three cases, described thrombosis of the basilar artery in a 22-year-old male in whom no cause could be found, apart from his suggestion of the possible contributing factors of excessive indulgence in smoking and alcohol and prolonged lack of sleep. Haase and Luhan (1959), Siekert and Millikan (1955), and Fang and Palmer (1956) reported cases, all middleaged or over.

Of the present two cases, the first one probably represents thrombosis secondary to inflammatory damage in the wall of the artery, although this could not be convincingly demonstrated in the microscopic sections. In the second case, despite bilateral thalamic lesions and minute scattered lesions in the midbrain, the obstruction was found in only one posterior cerebral artery. Therefore, either the primary obstruction must have occurred in the anterior end of the basilar artery and then subsequently moved onwards, or a second, undiscovered obstruction must have occluded the branches to the thalamus arising from the opposite posterior cerebral artery (Fig. 3), as in Kubik and Adams's Case 16. Embolism seems the more likely cause of the obstruction in this case, but no evidence of a site of origin in the heart or lungs could be demontrated, nor any general condition which could predispose to thrombosis in these organs.

Previous authors have dealt in detail with the clinical features of basilar artery occlusion, describing disturbances of consciousness, difficulty in speaking and swallowing, ocular abnormalities, hemiplegia and quadriplegia. Comment is usuaily made on the prominence of disturbances of consciousness, varying from coma to drowsy states and to forms resembling akinetic mutism. In the present two cases, although pupillary and corticospinal tract signs were present, the dominant feature was loss of consciousness. Kubik and Adams found disturbances of consciousness in cases where lesions involved only the thalamus and also where damage was confined to the lower twothirds of the pons. These findings correlate well with the observations of various authors on the collective importance of reticular nuclei in the brain stem, and of nuclei in the hypothalamus and thalamus, in the regulation of wakefulness (Feldberg, 1959). Much of this work has been brought together in the symposium arranged by the Council for International Organizations of Medical Sciences (1954).

The changes in the lower jaw of Case 1 were not due to osteomyelitis; they could have been produced by small emboli not demonstrated at autopsy, but as this case and another similar one associated with burns are being reported elsewhere the subject will not be pursued here.

\section{Summary}

Two children suddenly became unconscious, one in the course of septicaemia following burns, the other during apparently normal health. Death occurred five days and 10 weeks respectively from the onset of coma.

At autopsy occlusion of the region of the anterior end of the basilar artery was demonstrated, with softening of parts of the midbrain and thalamus. In the second case no explanation of the cause of the obstruction could be offered.

A brief review of the literature is given to indicate the rarity of basilar artery occlusion in children.

Thanks are due to the Board of the Adelaide Children's Hospital, to Mr. D. N. Robinson and to Dr. Ivan Magarey for permission to publish details of these cases. I am grateful to Mrs. Helga Thiede for technical assistance and to Mr. Ray Boyd for the preparation of the illustrations.

\section{REFERENCES}

Biemond, A. (1951). Thrombosis of the basilar artery and the vascularization of the brain stem. Brain, 74, 300 .

Council for International Organizations of Medical Sciences (1954) Symposium: Brain Mechanisms and Consciousness, ed. J. F. Delafresnaye. Blackwell, Oxford.

Cravioto, H., Rey-Bellet, J., Prose, P. H. and Feigin, I. (1958) Occlusion of the basilar artery. Neurology, 8, 145.

Fang, H. C. H. and Palmer, J. J. (1956). Vascular phenomena involving brain stem structures. ibid., 6, 402

Feldberg, W. (1959). A physiological approach to the problem of general anaesthesia and of loss of consciousness. Brit. med. J., 2,771 .

Haase, E. and Luhan, J. (1959). Protracted coma from delayed thrombosis of basilar artery following electrical injury. A.M.A. Arch. Neurol., 1, 195.

Hansen, J. (1958). 'Zum Krankheitsbild der Basilaristhrombose. Dtsch. Z. Nervenheilk., 177, 527.

Kubik, C. S. and Adams, R. D. (1946). Occlusion of the basilar artery-A clinical and pathological study. Brain, 69, 73.

Siekert, R. G. and Millikan, C. H. (1955). Studies in cerebrovascular disease. II. Some clinical aspects of thrombosis of the basilar artery. Proc. Mayo Clin., 30, 93. 
special conditions, diets, antibiotics, corticosteroids, and finally 15 pages of dosage of important drugs. These are in the metric system.

A few minor alterations are needed: Digoxin injection contains $10 \%$ alcohol not $20 \%$ (p. 6.4). Piperazine is given in a single dose for roundworms (p. 8.1), and the doses for sulphadiazine, sulphadimidine, sulphafurazole and sulphamethizole are higher than those used in some other hospitals. In addition, on p. 11.4 oral, intramuscular and intravenous doses for 'ledermycin' are given, and this drug is only ever given orally.

The Medical Annual, 1961. 79th issue. (Pp. liii +610 ; 32 figures +75 plates. 42s.) Bristol: John Wright. 1961.

The 79th issue of the Medical Annual appears in its usual format. The editors pay fitting tribute to the work done for the Annual over the years by Sir Henry Letheby Tidy, K.B.E., who joined the editorial staff in 1934, and to his modesty, sense of humour and gentleness.

There are as usual, four special articles: on Human Chromosome Abnormalities (W. M. Court Brown); the Management of Paraplegia (L. Guttmann); Microsurgery (J. Angell James); and the Psychotropic Drugs and Psychopharmacology (Linford Rees). Of these, the last is perhaps the most useful and informative, though the uncritical reader might begin to believe that in the future the manipulation of the personality lies with the chemical environment rather than through psychology.

In the section on Children's Diseases, Dr. George Newns deals with the year's work relating to toxicity of chloramphenicol, the masculinizing effects of progesterone-like substances, respiratory distress and sudden unexpected deaths. Surprisingly in 1955, according to the Registrar-General, no less than $20 \%$ of deaths from 2 weeks to 2 years occurred suddenly and unexpectedly.
Mr. R. E. Horton discusses congenital biliary atresia and diaphragmatic hernias (and laconically suggests that hiatus hernia in infancy is a less serious problem than has been suggested by some surgeons).

Under Child Psychiatry, Kenneth Cameron reports that the 'topic of interest during the past year has undoubtedly been cases of school phobia', and his review is interesting to read, though it is not easy to conclude from his many references how seriously to take this symptom of maladjustment to the human environment.

There are many reviews outside the section for children of interest to the paediatrician.

In general two criticisms are offered: First, that occasionally subjects seem to come in for unnecessary repetition, as for instance chromosomes, which are adequately dealt with in one article and sketchily treated in three others; and the rubella syndrome, the RegistrarGeneral's report on which is summarized at least four times. Secondly, the reviewer finds that the brevity of some reviews is such as to render them almost useless except as a source of references. Long reviews, such as the eight pages on ulcerative colitis, or even the illuminating two pages on the natural history of haemangiomata, are informative and allow the reader to come away with a good understanding of recent opinion, whereas a 10-line discussion on the year's work on obesity, or 12 lines on gastric polyps leave very little impression.

There are 75 plates, one in colour of the fundus oculi. The practitioner's index of recent pharmaceutical and dietetic preparations occupies 15 pages, and a list of English and American works of new editions, 19 pages. The general index is adequate for its purpose. The illustrations, print and paper are excellent, and the binding as before.

The publishers draw attention to an important error in Table 3 (page 41) in which the dose of tranquillizer drugs is given in grams instead of milligrams.

\section{Erratum}

The Author (M. Fowler) regrets an error in the captions to Figs. 1 and 3 of his article 'Two Cases of Basilar Artery Occlusion in Childhood' which appeared in this journal (Arch. Dis. Childh. 37, 78). 'Communicating' should read 'cerebral'. 